\title{
Characterisation of the fibre composition of common grass species under varying management conditions
}

C King ${ }^{1,2}$, J McEniry ${ }^{1}$, M Richardson ${ }^{2}$, P O'Kiely $^{1}$

${ }^{1}$ Teagasc, Grange Beef Research Centre, Dunsany, Co. Meath, Ireland

${ }^{2}$ University College Dublin,School of Architecture, Landscape \& Civil Engineering, Belfield, Dublin 4, Ireland

Email: colman.king@teagasc.ie

Introduction Ninety-one percent of agricultural land in Ireland is devoted to grass, making it the most important agricultural crop. Traditionally, grass and grass silage have formed the backbone of most beef and dairy production systems. However, in recent years interest has developed in alternative uses for grasslands and the potential of grass as a value added material (Kromus et al., 2004). The fibre fraction represents the largest proportion of the grass plant, so that if grass is to be used for value added material the fibre composition needs to be quantified. The purpose of this study was to determine the chemical fibre of a range of common grasses, harvested at different stages of maturity and under different nitrogen fertiliser regimes.

Material and methods Five common grass species (Lolium perenne L. var. Gandalf, Lolium multiflorum var. Prospect, Dactylis glomerata var. Pizza, Phleum pratense var. Erecta, Festuca arundinacea var. Fuego) were grown in field plots (each $20 \mathrm{~m}^{2}$; with triplicate replication; $\mathrm{n}=150$ ) under two nitrogen fertiliser inputs (low $\left.=0 \mathrm{~kg} / \mathrm{ha}, \mathrm{high}=125 \mathrm{~kg} / \mathrm{ha}\right) \mathrm{and}$ harvested at five dates (fortnightly from 12 May - 7 July; Harvests 1-5) in the primary growth. On each harvest date the plots were harvested with a Haldrup forage plot harvester and weighed to estimate herbage yield. A representative herbage sample was then taken from each plot for chemical analysis. Samples were oven dried at $40^{\circ} \mathrm{C}$ for 48 hours, milled through a $1 \mathrm{~mm}$ screen and was then analysed for neutral detergent fibre (NDF) and acid detergent fibre (ADF) concentrations using an ANKOM fibre analyser according to the method of Van Soest (1963). Data were analysed as a split-split plot design using the MIXED procedure of SAS, Version 9.1.2 (SAS, 2004).

Results and Discussion The NDF and ADF concentrations increased $(\mathrm{P}<0.001)$ with advancing plant maturity. On average, NDF concentration was highest $(\mathrm{P}<0.001)$ for Phleum pratense and lowest $(\mathrm{P}<0.001)$ for Lolium multiflorum (Figure 1). The ADF concentration was also highest $(\mathrm{P}<0.001)$ for Phleum pratense, followed by Dactylis glomerata, with values for Lolium perenne and Festuca arundinacea being similar (Figure 2). As harvest date advanced chemical fibre concentration increased $(\mathrm{P}<0.001)$ for all grass species, with the exception of Phleum pratense and Dactylis glomerata where a decrease in NDF concentration was observed from harvest period 4 to 5 . On average, ADF concentration was higher $(\mathrm{P}<0.05)$ for the high $\mathrm{N}$ fertiliser treatment, however, the difference was negligible. No further significant interactions were observed.

$$
\begin{aligned}
& \text { s.e.m }=7.01 \\
& * * *
\end{aligned}
$$

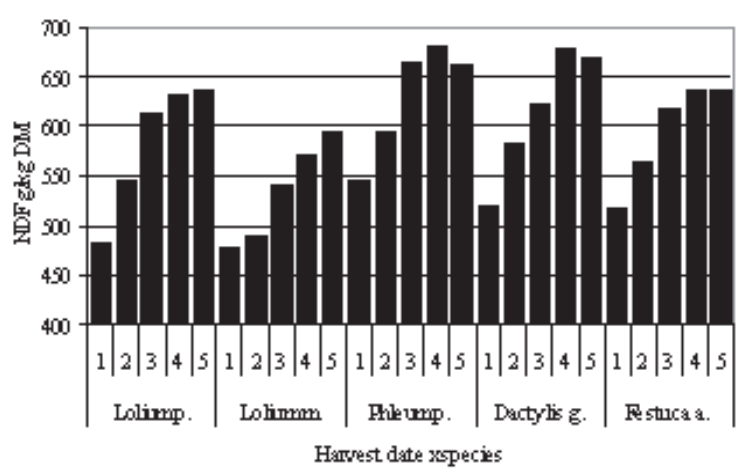

Figure 1 NDF concentration of five grass species across five harvest dates

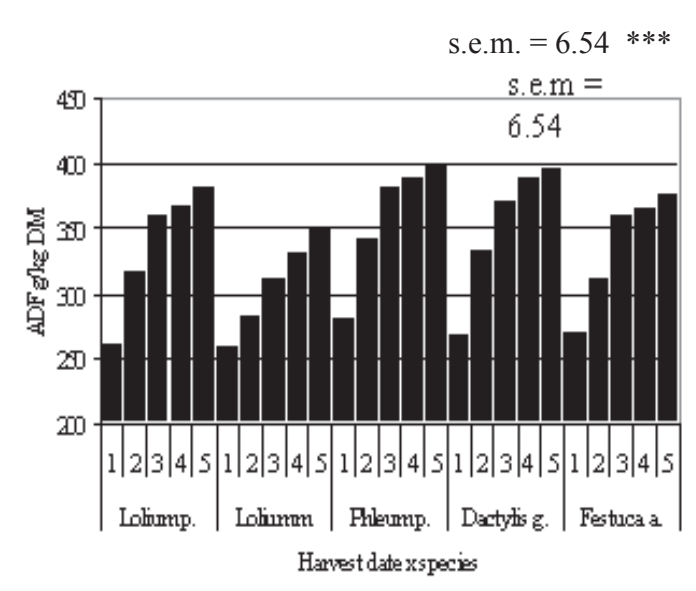

Figure 2 ADF concentration of five grass species across five harvest dates

Conclusion Grass fibre concentration increased with increasing plant maturity. Of the five grasses examined, Phleum pratense had the highest fibre concentration. Further study will involve the determination of the lignin concentration of each grass and the physical characterisation of the grass fibre.

Acknowledgements Funding for this research was provided under the National Development Plan, through the Research Stimulus Fund, administered by the Department of Agriculture, Fisheries \& Food, Ireland \#RSF 07557

\section{References}

SAS 2004. SAS for windows, Version 9.1.2, Statistical Analysis System, Institute Inc., Cary, North Carolina, USA.

Van Soest, P. J. 1963. Journal of Association of Official Analytical Chemists. 46, 829-835.

Kromus, S., Wachter, B., Koschuh, W., Mandl, M., Krotscheck, C. and Narodoslawsky, M. 2004. Chemical and Biochemical Engineering Quarterly 18: 1, 7-12. 